\title{
Branched-chain amino acid supplements reduced ascites and increased the quality of life in a patient with liver cirrhosis: A case report
}

\author{
MINORU ITOU $^{1}$, TAKUMI KAWAGUCHI ${ }^{1,2}$, EITARO TANIGUCHI ${ }^{1}$, YUICHIRO OKU ${ }^{1}$, NOBUYOSHI FUKUSHIMA ${ }^{1}$, \\ EIJI ANDO ${ }^{1}$, TETSUHARU ORIISHI ${ }^{1}$, YUKI UCHIDA ${ }^{3}$, MOMOKA OTSUKA $^{3}$, SUIKO TANAKA ${ }^{3}$, SHOKO IWASAKI ${ }^{3}$, \\ MARI TORII ${ }^{4}$, KIYOMI YOSHIDA ${ }^{4}$, YUKO ADACHI ${ }^{4}$, MARIKO SUGA $^{4}$, MANAMI YOSHIYAMA $^{4}$, RYOKO IBI $^{4}$, \\ YOSHIKO AKIYAMA ${ }^{4}$, MACHIKO TAKAKURA ${ }^{4}$, KEIICHI MITSUYAMA ${ }^{1}$, OSAMU TSURUTA ${ }^{1}$ and MICHIO SATA ${ }^{1,2}$ \\ ${ }^{1}$ Division of Gastroenterology, Department of Medicine, ${ }^{2}$ Department of Digestive Disease Information and Research, \\ Kurume University School of Medicine; Departments of ${ }^{3}$ Nutrition, and ${ }^{4}$ Nursing, \\ Kurume University Hospital, Kurume 830-0011, Japan
}

Received November 11, 2008; Accepted April 10, 2009

DOI: $10.3892 / \mathrm{mmr} 00000201$

\begin{abstract}
Liver cirrhosis is frequently accompanied by malnutrition and hypoalbuminemia, which in turn commonly induces ascites in patients with liver cirrhosis. Ascites leads to abdominal distention and appetite loss, resulting in a deteriorated quality of life (QOL). Administration of branched-chain amino acid (BCAA)-rich supplements reduces hepatic encephalopathy and malnutrition. In addition, BCAAs by themselves up-regulate albumin synthesis through an increase in Fisher's ratio. Thus, in patients with liver cirrhosis, BCAA-rich supplements seem to be effective at reducing ascites and improving the QOL. Here, we report the case of a 58-year-old Japanese man with liver cirrhosis with severe ascites and peripheral edema. The hepatic function of the patient was classified as Child-Pugh grade C. To reduce protein-energy malnutrition, BCAA-rich supplements were administered as a late evening snack as part of a regimen including $2000 \mathrm{kcal} /$ day ( $32.5 \mathrm{kcal} / \mathrm{kg} / \mathrm{day})$ of total energy and $83.5 \mathrm{~g} /$ day $(1.3 \mathrm{~g} / \mathrm{kg} /$ day $)$ of total protein intake. Eight weeks after admission, ascites and edema had decreased. Nutritional status also improved from the time of admission to discharge; the serum BCAA level increased from 365.4 to $450.2 \mu \mathrm{mol} / 1$. Furthermore, the ratio of BCAAs to tyrosine (BTR) increased from 1.70 to 3.65. We also evaluated the effects of nutritional therapy on the patient's QOL using the Medical Outcomes Study 36-Item Short-Form Health Survey upon admission and at discharge. All subscores showed marked improvement and
\end{abstract}

Correspondence to: Dr Minoru Itou, Division of Gastroenterology, Department of Medicine, Kurume University School of Medicine, 67 Asahi-machi, Kurume 830-0011, Japan

E-mail: itou74m@med.kurume-u.ac.jp

Key words: branched-chain amino acids, ascites, liver cirrhosis reached a level greater than the Japanese norm with nutritional treatment. In conclusion, BCAA supplementation not only reduced ascites, but also improved the QOL in a patient with liver cirrhosis.

\section{Introduction}

Liver cirrhosis is frequently accompanied by malnutrition and hypoalbuminemia $(1,2)$. Hypoalbuminemia is closely associated with the development of ascites in patients with liver cirrhosis (1). Ascites induces abdominal distension and anorexia, leading to increased hypoalbuminemia as well as to a reduced quality of life (QOL) (1). At present, diuretic agents and the infusion of albumin are the only palliative treatment for ascites. However, these therapies do not up-regulate endogenous albumin synthesis.

The administration of branched-chain amino acid (BCAA)rich supplements reduces hepatic encephalopathy (3-5). Recently, branched-chain amino acid (BCAA) supplementation was shown to improve nutritional status (6). Decreases in the ratio of BCAAs to aromatic amino acids (AAAs) (Fisher's ratio) are associated with the severity of liver disease. BCAArich supplements up-regulate albumin synthesis through an increase in Fisher's ratio (7). Thus, in patients with liver cirrhosis, BCAA supplementation seems to be effective at reducing ascites and improving QOL.

Here, we report a case of BCAA supplementation that reduced ascites and improved the QOL in a patient with liver cirrhosis.

\section{Case report}

A 58-year-old Japanese man was referred to Kurume University Hospital for the treatment of hepatocellular carcinoma (HCC). $\mathrm{HCV}$ infection had been diagnosed by a positive result for serum HCV antibody when the patient was 48 years old. At the age of 52, liver cirrhosis was diagnosed. However, the 


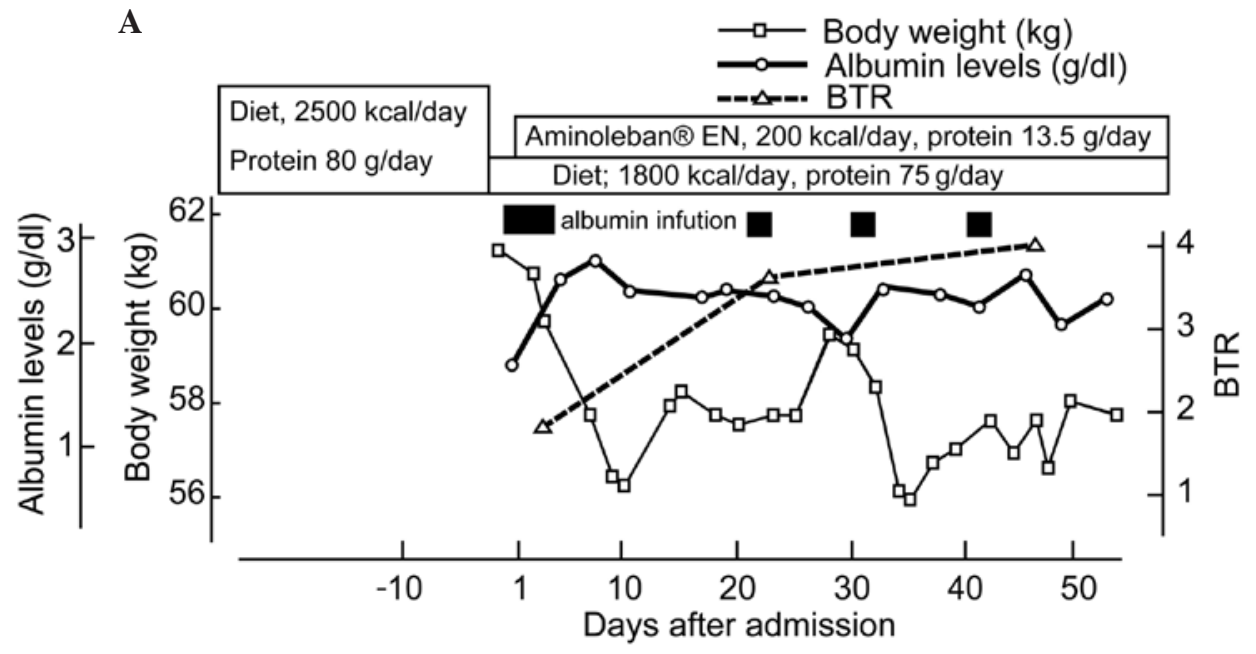

B

C
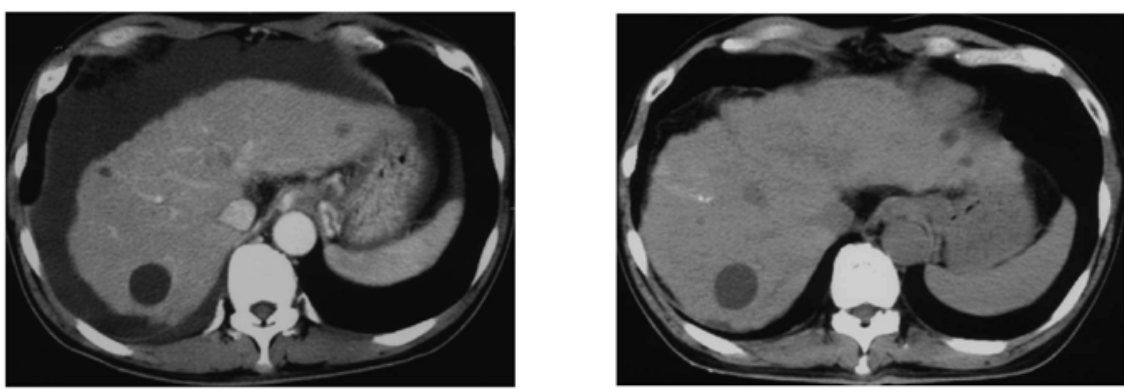

D
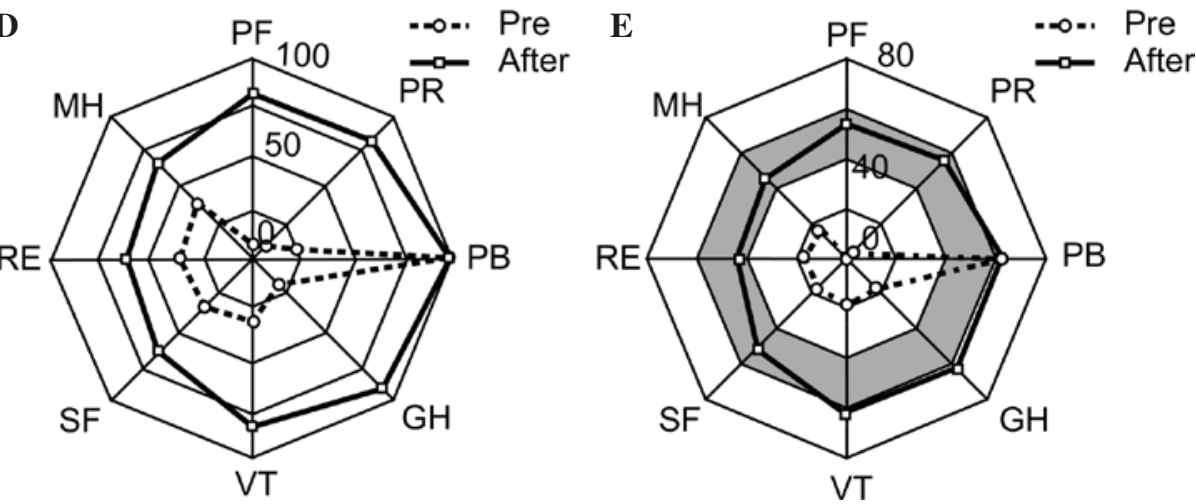

Figure 1. (A) Laboratory indices for the indicated days after admission. Prior to admission, the patient had a $2500 \mathrm{kcal} / \mathrm{day}$ energy and $80 \mathrm{~g} / \mathrm{day}$ protein intake. After admission, he began nutritional treatment: a $1800 \mathrm{kcal} /$ day energy with $75 \mathrm{~g} /$ day protein diet and $50 \mathrm{~g}$ of Aminoleban ${ }^{\circledast} \mathrm{EN}$ (Table I) with abundant BCAAs as a late evening snack. Total energy intake was $2100 \mathrm{kcal} / \mathrm{day}(32.5 \mathrm{kcal} / \mathrm{kg} /$ day $)$ and total protein intake was at least $83.5 \mathrm{~g} / \mathrm{day}(1.3 \mathrm{~g} / \mathrm{kg} / \mathrm{day})$. At admission, the serum albumin level was $1.79 \mathrm{~g} / \mathrm{dl}$. However, this gradually increased and was maintained at $2.6 \mathrm{~g} / \mathrm{dl}$. The serum BCAA level increased from 365.4 to $450.2 \mu \mathrm{mol} / 1$, and the BTR increased to 3.65 from 1.70 at admission. (B and C) Computed tomography of abdomen. At admission, severe ascites was noted in the abdomen (B). On day 41, a marked decrease of ascites was noted in a CT scan of the abdomen (C). (D and E) Changes in SF-36v2 score after nutritional supplementation as part of the prescribed diet. D shows the actual score on a scale of 0 to 100, and E shows the norm-based score. PF, physical functioning; RP, physical role; BP, bodily pain; GH, general health; VT, vitality; SF, social functioning; RE, emotional role; $\mathrm{MH}$, mental health.

patient did not regularly take medication. At the age of 58 , he underwent examinations due to a complaint of fullness in his abdomen. At that time, severe ascites and HCC were detected by ultrasonography (US) at the outpatient clinic of Kurume University Hospital. The patient was admitted to our hospital for the treatment of ascites and HCC. Physical examination upon admission showed that the patient had a height of $168.5 \mathrm{~cm}$, weight of $61.4 \mathrm{~kg}$ and body mass index (BMI) of $21.6 \mathrm{~kg} / \mathrm{m}^{2}$. The required energy expenditure of this patient was estimated to be $1968 \mathrm{kcal} / \mathrm{day}$, and the daily protein intake to be from 75 to $94 \mathrm{~g} /$ day $(1.2-1.5 \mathrm{kcal} / \mathrm{kg} /$ day) based on the European Society for Clinical Nutrition and Metabolism (ESPEN) Guidelines on Enteral Nutrition: Liver Disease (8). Prior to admission, the patient's average energy intake had been $2500 \mathrm{kcal} /$ day, with a protein intake of $80 \mathrm{~g}$ /day (Fig. 1A). Vital signs were within normal ranges. The patient had peripheral edema, tense ascites and umbilical hernia. Laboratory data at admission are summarized in Table II. The hepatic function of the patient was 
Table I. Composition of the BCAA-enriched supplement (Aminoleban $\mathrm{EN}^{\circledR}$, per $50 \mathrm{~g} / 200 \mathrm{ml}$ ).

\begin{tabular}{lc}
\hline Total energy & $210 \mathrm{kcal}$ \\
Protein & $13.5 \mathrm{~g}$ \\
Amino acids (Fischer's ratio = 38) & \\
L-valine & $1.60 \mathrm{~g}$ \\
L-leucine & $2.04 \mathrm{~g}$ \\
L-isoleucine & $1.92 \mathrm{~g}$ \\
L-threonine & $0.13 \mathrm{~g}$ \\
L-tryptophan & $0.07 \mathrm{~g}$ \\
L-arginine hydrochloride & $0.30 \mathrm{~g}$ \\
L-histidine hydrochloride & $0.19 \mathrm{~g}$ \\
L-lysine hydrochloride & $0.24 \mathrm{~g}$ \\
Fat (rice oil) & $3.50 \mathrm{~g}$ \\
Carbohydrates (dextrin) & $31.05 \mathrm{~g}$ \\
Vitamins & \\
Minerals & \\
Deionized water & \\
pH & $180 \mathrm{ml}$ \\
\end{tabular}

aVitamins include trace amounts of magnesium sulphate, calcium glycerophosphate, potassium iodide, potassium chloride, sodium dihydrogenphosphate dihydrate, sodium ferrous citrate, cupric sulphate, zinc sulphate and manganese sulphate. ${ }^{\mathrm{b}} \mathrm{Minerals}$ include retinol palmitate, ergocalciferol, bisbentiamine, riboflavin, pyridoxine $\mathrm{HCl}$, cyanocobal-amin, folic acid, sodium l-ascorbate, tocopherol acetate, phytonadione, calcium pantothenate, nicotinamide and biotin.

classified as Child-Pugh grade C. Severe ascites and HCC in segment 5 of the liver were noted in computed tomography (CT) images (Fig. 1B). On admission, serum albumin levels were $1.79 \mathrm{~g} / \mathrm{dl}$, and the serum BCAA to tyrosine ratio (BTR) was 1.70 . Therefore, we diagnosed the nutritional status of the patient as protein-energy malnutrition (PEM) with liver cirrhosis. To increase colloid osmotic pressure, a drip infusion of human albumin was administered from day 3 to 5. After the infusion of human albumin, serum albumin levels increased to $2.61 \mathrm{~g} / \mathrm{dl}$. In addition, to improve PEM in cirrhosis, $50 \mathrm{~g}$ of BCAA-rich supplementation (Aminoleban ${ }^{\circledR}$ EN; Table I) was provided as a late evening snack. Finally, total energy intake was $2000 \mathrm{kcal} /$ day (32.5 kcal/kg/day) and total protein intake was at least $83.5 \mathrm{~g} /$ day (1.3 g/kg/day) (Fig. 1A). During hospitalization, no significant changes were noted in total energy and protein intake after the administration of BCAA-rich supplements. However, the patient's edema gradually decreased and disappeared by day 44, while the serum albumin level gradually increased and was maintained at approximately $2.60 \mathrm{~g} / \mathrm{dl}$. The serum BCAA level increased from 365.4 to $450.2 \mu \mathrm{mol} / 1$. Furthermore, BTR increased to 3.65 from 1.70 at admission (Fig. 1A). Patient body weight was lower than it had been at admission (Fig. 1B). Thus, an improvment was seen in nutritional status, and the ascites disappeared by day 41 (Fig. 1C) as indicated by a CT scan. Finally, the HCC was treated successfully.
Table II. Laboratory data of the patient at admission.

\begin{tabular}{|c|c|}
\hline \multicolumn{2}{|l|}{ Hematology } \\
\hline WBC & 1800 count $/ \mu 1$ \\
\hline Lymphocytes & 198 count $/ \mu 1$ \\
\hline $\mathrm{RBC}$ & $311 \times 10^{4} \mathrm{count} / \mu$ \\
\hline Hemoglobin & $5.4 \mathrm{~g} / \mathrm{dl}$ \\
\hline Hematocrit & $19.4 \%$ \\
\hline Platelets & $13.2 \times 10^{4} \mathrm{count} / \mathrm{s}$ \\
\hline \multicolumn{2}{|l|}{ Biochemical examinations } \\
\hline AST & $26 \mathrm{U} / 1$ \\
\hline ALT & $15 \mathrm{U} / 1$ \\
\hline $\mathrm{LDH}$ & $161 \mathrm{U} / 1$ \\
\hline ALP & $323 \mathrm{U} / 1$ \\
\hline GGT & $22 \mathrm{U} / 1$ \\
\hline Total bilirubin & $0.44 \mathrm{mg} / \mathrm{dl}$ \\
\hline Total protein & $4.92 \mathrm{~g} / \mathrm{dl}$ \\
\hline Albumin & $1.79 \mathrm{~g} / \mathrm{dl}$ \\
\hline Total cholesterol & $90 \mathrm{mg} / \mathrm{dl}$ \\
\hline Fasting plasma glucose & $93 \mathrm{mg} / \mathrm{dl}$ \\
\hline Hyaluronate & $392 \mathrm{ng} / \mathrm{ml}$ \\
\hline Ammonia & 124 mg/dl \\
\hline BCAAs & $365.4 \mu \mathrm{mol} / 1$ \\
\hline Tyrosine & $215.1 \mu \mathrm{mol} / 1$ \\
\hline BTR & 1.7 \\
\hline $\mathrm{Zn}$ & $46 \mathrm{mg} / \mathrm{dl}$ \\
\hline AFP & $8.6 \mathrm{ng} / \mathrm{ml}$ \\
\hline DCP & $584 \mathrm{mAU} / \mathrm{ml}$ \\
\hline HBs-Ag & Negative \\
\hline $\mathrm{HCV}-\mathrm{Ab}$ & Positive \\
\hline
\end{tabular}

RBC, red blood cell count; WBC, white blood cell count; AST, aspartate aminotransferase; ALT, alanine aminotransferase; LDH, lactate dehydrogenase; ALT, alkaline phosphatase; GGT, $\gamma$-glutamyltranspeptidase; BCAA, branched-chain amino acids; BTR, BCAA to tyrosine ratio; AFP, $\alpha$-fetoprotein; DCP, des- $\gamma$-carboxyprothrombin; HBs-Ag, hepatitis B surface antigen; HCV-Ab, hepatitis C antibody.

The effects of nutritional therapy on the patient's QOL were also evaluated using the Medical Outcomes Study 36-Item Short-Form Health Survey version 2 (SF-36v2) at admission and on the day of discharge. With nutritional therapy, the patient scores improved: physical functioning $(\mathrm{PF})$ went from 10.0 to 95.0 ; physical role (PR) from 0.0 to 100 ; general health (GH) from 5.0 to 92.0 ; vitality (VT) from 0.0 to 87.5 ; social functioning (SF) from 25.0 to 87.5 ; emotional role (RE) from 25.0 to 75.0 ; mental health (MH) from 10.0 to 65.0 (Fig. 1D). All the scores showed marked improvement and reached a level that was greater than the Japanese norm-based scores seen with nutritional treatment (Fig. 1E).

The patient was discharged on day 59 and has continued nutritional therapy with $50 \mathrm{~g}$ of BCAA-rich supplements as a late evening snack. At a 12-month follow-up after discharge, the patient showed no edema or ascites, and had a serum albumin level of $2.39 \mathrm{~g} / \mathrm{dl}$, a serum BCAA level of $427.6 \mu \mathrm{mol} / 1$, and a BTR of 3.78 . 


\section{Discussion}

Here, we presented a case suggesting that the administration of BCAA-rich supplements reduces ascites and improves QOL in patients with liver cirrhosis.

BCAA-rich supplements are commonly used for the treatment of hepatic encephalopathy in patients with liver cirrhosis (3-5). In the present case, the administration of BCAA-rich supplements not only reduced hypoalbuminemia, but also reduced ascites. BCAA is known to reduce hypoalbuminemia in cirrhotic patients $(6,9)$. Previous studies have also reported that BCAAs promote albumin synthesis by improving amino acid imbalance. There are two possible mechanisms behind the ability of BCAA-rich supplements to reduce hypoalbuminemia. One is that an increased supply of substrate for protein synthesis causes increases in albumin synthesis. However, our patient had had an adequate daily energy and total protein intake prior to admission, and had not had a preference for consuming BCAA-rich foods, including whey protein and milk products. Fruits, polished rice and refined grains had been included in his daily diet. Thus, the ability of BCAAs to increase the supply of substrate for protein synthesis may increase albumin synthesis. Second, BCAAs facilitate protein synthesis by stimulating the initiation of albumin mRNA translation via the activation of intracellular signal transduction systems, particularly systems involving the mammalian target rapamycin (mTOR) (10-12). For these reasons, BCAAs may increase albumin synthesis and osmotic pressure, which may in turn result in a decrease in extracellular fluid and ascites. One would think that the injection of human albumin might contribute to the increase in serum albumin level. However, previous studies have shown that the half-life of albumin ranges from 5.52 to 11.76 days (13). In our case, the serum albumin level was maintained for more than 14 days after albumin injection. Therefore, we believe that administration of BCAA-rich supplements may contribute to reductions in hypoalbuminemia and ascites through an increased supply of substrate for protein and the stimulation of protein synthesis.

In this study, we also showed that BCAA supplementation improved QOL $(14,15)$. In this case, PF, PR, GH, VT, SF, RE and $\mathrm{MH}$ scores were significantly lower than the norm-based scores at admission. However, after nutritional treatment, all scores showed marked improvement and reached levels that were above the median for the Japanese population. On the other hand, previous reports showed that BCAAs did not improve the SF-36 score in cirrhotic patients $(9,16,17)$. Three possible mechanisms exist for the improvement in QOL observed in this case. First, marked retention of ascites was noted on admission. In general, the presence of ascites is significantly associated with a poor QOL in cirrhotic patients (18). As a result of BCAA-rich supplements, decreased ascites reduced abdominal tension. Thus, a reduction in ascites could be a factor leading to improved SF-36v2 scores. Second, BCAAs act directly on the central nervous system to reduce hepatic encephalopathy (19). Subclinical hepatic encephalopathy affects mental aspects of QOL (20). In this case, the elevation of ammonia levels and decreases in BTR suggest that the patient was suffering from subclinical hepatic encephalopathy. Through BCAA-rich supplements, the ammonia level decreased. Thus, an improvement in subclinical hepatic encephalopathy could be a factor leading to an improvement in SF-36 scores. Third, Yamamoto et al reported that cerebral blood flow is decreased in patients with hepatic encephalopathy, and that oral administration of BCAA increases regional cerebral blood flow (21). In addition, maintenance of adequate cerebral blood flow maintains the QOL (22). Thus, BCAAs might improve the QOL by maintaining the cerebral blood flow.

In conclusion, we report a case in which BCAA-rich supplements improved not only ascites, but also QOL in a patient with liver cirrhosis. Thus, BCAA-rich supplementation may be a new therapeutic agent for cirrhotic patients with ascites.

\section{References}

1. Miwa Y and Moriwaki H: Nocturnal energy and BCAA supplementation in patients with liver cirrhosis. Hepatol Res 30S: 63-66, 2004.

2. Moriwaki H, Miwa Y, Tajika M, Kato M, Fukushima H and Shiraki M: Branched-chain amino acids as a protein- and energysource in liver cirrhosis. Biochem Biophys Res Commun 313: 405-409, 2004.

3. Sato S, Watanabe A, Muto $\mathrm{Y}$, et al: Clinical comparison of branched-chain amino acid (1-Leucine, 1-Isoleucine, 1-Valine) granules and oral nutrition for hepatic insufficiency in patients with decompensated liver cirrhosis (LIV-EN study). Hepatol Res 31: 232-240, 2005.

4. Fukuda K, Yao H, Murai K, Ibayashi $\mathrm{S}$ and Fujishima M: Long-term treatment of portosystemic encephalopathy with oral branched-chain amino acids - a case report. Fukuoka Igaku Zasshi 90: 464-469, 1999.

5. Higuchi K, Shimizu Y, Nambu S, et al: Effects of an infusion of branched-chain amino acids on neurophysiological and psychometric testings in cirrhotic patients with mild hepatic encephalopathy. J Gastroenterol Hepatol 9: 366-372, 1994.

6. Habu D, Nishiguchi S, Nakatani S, et al: Effect of oral supplementation with branched-chain amino acid granules on serum albumin level in the early stage of cirrhosis: a randomized pilot trial. Hepatol Res 25: 312-318, 2003.

7. Suzuki K, Suzuki K, Koizumi K, et al: Measurement of serum branched-chain amino acids to tyrosine ratio level is useful in a prediction of a change of serum albumin level in chronic liver disease. Hepatol Res 38: 267-272, 2008.

8. Plauth M, Cabre E, Riggio O, et al: ESPEN Guidelines on Enteral Nutrition: Liver Disease. Clin Nutr 25: 285-294, 2006.

9. Nakaya Y, Okita K, Suzuki K, et al: BCAA-enriched snack improves nutritional state of cirrhosis. Nutrition 23: 113-120, 2007.

10. Hara K, Yonezawa K, Weng QP, Kozlowski MT, Belham C and Avruch J: Amino acid sufficiency and mTOR regulate p70 S6 kinase and eIF-4E BP1 through a common effector mechanism. J Biol Chem 273: 14484-14494, 1998.

11. Ijichi C, Matsumura T, Tsuji T and Eto Y: Branched-chain amino acids promote albumin synthesis in rat primary hepatocytes through the mTOR signal transduction system. Biochem Biophys Res Commun 303: 59-64, 2003.

12. Nishitani $\mathrm{S}$ and Takehana K: Pharmacological activities of branched-chain amino acids: augmentation of albumin synthesis in liver and improvement of glucose metabolism in skeletal muscle. Hepatol Res 30S: 19-24, 2004.

13. Spiess A, Mikalunas V, Carlson S, Zimmer M and Craig RM: Albumin kinetics in hypoalbuminemic patients receiving total parenteral nutrition. JPEN J Parenter Enteral Nutr 20: 424-428, 1996.

14. Fukuhara S, Bito S, Green J, Hsiao A and Kurokawa K: Translation, adaptation, and validation of the SF-36 Health Survey for use in Japan. J Clin Epidemiol 51: 1037-1044, 1998.

15. Kawaguchi T, Taniguchi E, Itou M, et al: Appearance-specific satiety increases appetite and quality of life in patients with metastatic liver tumor: a case report. Kurume Med J 53: 41-46, 2006.

16. Marchesini G, Bianchi G, Merli M, et al: Nutritional supplementation with branched-chain amino acids in advanced cirrhosis: a double-blind, randomized trial. Gastroenterology 124: 1792-1801, 2003. 
17. Kawamura N, Nakajima $\mathrm{H}$ and Takashi SI: Administration of granulated BCAA and quality of life. Hepatol Res 30S: 42-45, 2004.

18. Saab S, Ibrahim AB, Shpaner A, et al: MELD fails to measure quality of life in liver transplant candidates. Liver Transpl 11: 218-223, 2005

19. Watanabe A: Cerebral changes in hepatic encephalopathy. J Gastroenterol Hepatol 13: 752-760, 1998.

20. Arguedas MR, DeLawrence TG and McGuire BM: Influence of hepatic encephalopathy on health-related quality of life in patients with cirrhosis. Dig Dis Sci 48: 1622-1626, 2003.
21. Yamamoto M, Iwasa M, Matsumura K, et al: Improvement of regional cerebral blood flow after oral intake of branched-chain amino acids in patients with cirrhosis. World J Gastroenterol 11: 6792-6799, 2005

22. Immer FF, Lippeck C, Barmettler H, et al: Improvement of quality of life after surgery on the thoracic aorta: effect of antegrade cerebral perfusion and short duration of deep hypothermic circulatory arrest. Circulation 110: II250-II255, 2004. 